International Journal of Advanced Biological and Biomedical Research

Available online at http:www.ijabbr.com

Volume 8, Issue 3 (2020) pp. 302-313

DOI: 10.33945/SAMI/IJABBR.2020.3.8

Original Article

\title{
Reinforcement of a Decellularized Extracellular Matrix- Derived Hydrogel Using Nanofibers for Cardiac Tissue Engineering
}

\author{
Shohreh Mashayekhan ${ }^{*}$, Mahboubeh Jafarkhani' ${ }^{2}$, Saeed Moghadam1 \\ ${ }^{1}$ Department of Chemical and Petroleum Engineering, Sharif University of Technology, \\ Tehran, 11365-8639, Iran \\ ${ }^{2}$ School of Chemical Engineering, College of Engineering, University of Tehran, Iran \\ *Corresponding Author E-mail: mashayekhan@sharif.edu
}

Received: 27 December 2019, Revised: 15 February 2020, Accepted: 26 February 2020

\begin{abstract}
The role of heart disease in increasing worldwide death and the limited availability of organs for transplantation have encouraged multiple strategies to fabricate functional and implantable constructs. One of these strategies is to develop a biologically similar heart tissue scaffold, in which two types of fiber and hydrogel are commonly used. Toward this goal, taking advantage of both hydrogels properties and fibers features with excellent mechanical properties can be considered as a promising method. The purpose of this study was to develop a fiber/hydrogel composite of gelatin, poly-caprolactone (PCL), cardiac extracellular matrix (ECM), and chitosan. The fibrous scaffolds of PCL and gelatin were characterized by SEM, water drop contact angle test, FTIR, and mechanical tests. The results showed that the average diameter of nanofibers, hydrophilicity and mechanical properties of the fibrous scaffolds increased with increasing the gelatin content in the spinning solution. Furthermore, the results of mechanical tests indicated that by integrating fibers with gelatin to PCL mass ratio of 2 in the hydrogel of chitosan and ECM with a mass ratio equal to 1 , we obtained a construct with similar mechanical properties to native heart tissue, which may be proposed as an appropriate scaffold for heart tissue engineering.
\end{abstract}

Key words: Cardiac tissue engineering, Composite scaffold, Extracellular matrix, Mechanical properties, Nanofiber

\section{Introduction}

Today, cardiovascular has a key factor in most of human deaths annually. Given the shortage of organ donors, cardiac tissue engineering has been emerged as a promising approach for cardiac regeneration using biomimetic scaffolds and cardiomyocytes (Jafarkhani et al., 2018; $\mathrm{Hu}$ et al., 2019). An interesting method in cardiac tissue engineering is to develop functional 
biomimetic 3D constructs incorporating biocompatible and biodegradable nanofibers and hydrogels with suitable mechanical strength (Ying et al., 2011).

An ideal biomaterial for cardiac tissue regeneration should imitate the micro-structure of the native tissue, presents an appropriate mechanical strength, and has electroactive properties to direct cardiac cell behaviors. Up to now, development of such functional biomaterial is still a big challenge (Pomeroy et al., 2019).

Recently, some success has been achieved in developing nano-fibrous biomaterials with morphological similarity to the cardiac ECM. (Ismail et al., 2018; Ahn et al., 2018; Su et al., 2016). Using electrospinning, biomimetic nano-fibrous constructs with tunable properties can be developed easily by changing biomaterials composition and processing factors (Yang et al., 2016). Numerous kinds of fibrous scaffolds have been fabricated as heart muscle patches. A rigid and non-elastic fibrous patch may prevent cardiac tissue from its normal motion. To overcome this challenge and provide a 3D environment for cells, hydrogels are usually employed as a bed to surround the fibers and control different growth factors release (Ying et al., 2011).

PCL is an interesting synthetic polymer which can be easily processed to achieve an implantable scaffold (Siddiqui et al., 2018). However, the use of PCL alone as a scaffold material is limited due to its hydrophobic properties and poor cell attachment (Kucinska-Lipka et al., 2015). Therefore, blending a natural polymer such as gelatin (Zhao et al., 2007) and collagen (Jin et al., 2009) with PCL is expected to modulate its bioactivity, degradation rate, and hydrophilicity (Kucinska-Lipka et al., 2015).

The combination of PCL and gelatin has been studied in the previous studies (Chong et al., 2007; Zhang et al., 2005; Zhao et al., 2007). In most of these studies, a solvent was used to dissolve gelatin and PCL. For example, hexafluoro-2-propanol was employed as a common solvent for PCL and gelatin. However, this solvent is toxic and unavailable. Due to the fact that there is no common, non-toxic, and well-known solvent for both PCL and gelatin, researchers have sought to find a suitable solvent. For example, (Gautam et al., 2013) used acetic acid for gelatin and chloroform/methanol for PCL. They claimed that with this solvent system, it is possible to try these two polymers in one syringe. Regarding the literature review, in this study, two syringes were used to electrospin two solutions separately.

In the present study, we first investigated the appropriate composition for fibrous scaffolds and hydrogels separately based on heart tissue features. PCL and gelatin were used for fibers fabrication. For hydrogel composition, the best material is ECM derived from the heart due to its similarity to the native cardiac tissue. In order to improve the mechanical properties of the ECM-derived hydrogel, chitosan was applied. Therefore, a new biomaterial composition was developed from PCL/gelatin fiber embedded within the hydrogel of chitosan and ECM to use in cardiac tissue engineering.

\section{Experimental}

\section{Materials and methods}

PCL, gelatin, sulfuric acid $\left(\mathrm{H}_{2} \mathrm{SO}_{4}\right)$, Phosphoric acid $\left(\mathrm{H}_{3} \mathrm{PO}_{4}\right)$, hexafluoro-2 propanol, sodium dodecyl sulfate (SDS) were bought from Sigma-Aldrich. To crosslink the samples, glutaraldehyde was obtained from Merck. 


\section{Decellularization}

Decellularization of the bovine heart was performed using enzymatic detergent based on SeifNaraghi's protocol (Singelyn et al., 2009). Briefly, the bovine heart was kept on ice during transportation to the laboratory to avoid matrix damage. Then the heart was cut to the thin sheets with $2 \mathrm{~mm}$ thickness and then washed with PBS solution for $2 \mathrm{~h}$. Next, the samples were immersed in SDS solution $(0.1 \% \mathrm{w} / \mathrm{v})$ in the presence of protease inhibitors and placed in the shaker-incubator for $24 \mathrm{~h}$ three times. The tissues were finally washed with a Triton X-100 solution $(1 \% \mathrm{v} / \mathrm{v})$, and then with sterile PBS for $24 \mathrm{~h}$ with vigorous stirring, frozen overnight at $-70^{\circ} \mathrm{C}$ and lyophilized for $48 \mathrm{~h}$. The decellularized powder was dissolved in pepsin solution (1 $\mathrm{mg} / \mathrm{mL})$.

\section{Hydrogel fabrication}

Hydrogel samples were fabricated according to a certain protocol, which was optimized for cardiac tissue engineering applications and reported by Esmaeili et al (Esmaeili Pourfarhangi et al., 2018). Briefly, a chitosan solution (3.5\% wt.) was prepared in acetic acid (2\% v/v) under agitation condition at $60{ }^{\circ} \mathrm{C}$ for $24 \mathrm{~h}$. To make ECM solution, initially $0.1 \mathrm{M}$ HCL solution was made and $1 \mathrm{mg}$ of pepsin was dissolved in $1 \mathrm{Ml}$ of acid solution (pepsin solution). Then, $10 \mathrm{mg}$ of decellulaized ECM was dissolved in pepsin solution for about 65h stirring. After that, by adding 1 $\mathrm{M} \mathrm{NaOH}$ and PBS 10X, the solution was reached to $\mathrm{pH}$ 7.4. ECM and chitosan solutions were then mixed with the same volume ratio and then stirred for $2 \mathrm{~h}$ to obtain a homogenous solution.

\section{Electrospinning}

Here, two-nozzle electrospinning method was applied to produce nanofibers from PCL and gelatin. A syringe containing PCL solution (in chloroform/dimethylformamide solvent with volumetric ratio of 4 to 1) and another syringe of gelatin solution was used. Gelatin solution in acetic acid (25\% wt.) was prepared under agitation for $24 \mathrm{~h}$. Then, PCL and gelatin solutions were poured in two separate syringes located at 16 and $24 \mathrm{~cm}$ and two voltages of 17 and 11 $\mathrm{kV}$ were applied to the needle of each syringes, respectively. By changing the flow rate of both solutions, samples with different properties can be obtained. Three groups of the fibrous samples were fabricated with different gelatin to PCL mass ratio of 1,2 , and 3 , which termed as GP1, GP2, and GP3. For production of GP1, GP2, and GP3, flow rate ratios of PCL to gelatin were $0.2 / 0.1,0.5 / 0.5$, and $0.3 / 0.5$, respectively. Finally, glutaraldehyde steam was used to crosslink the polymeric fibers.

\section{Fiber/hydrogel composite fabrication}

Fibrous scaffolds of PCL/gelatin were embedded within the hydrogel of chitosan and ECM. To create the constructs from hydrogel and fibers, the fibrous scaffolds were cut in $3 \times 2 \mathrm{~cm}$ and then embedded in $10 \mathrm{~mL}$ hydrogel solution for $5 \mathrm{~min}$. In the next step, $10 \mu$ l glutaraldehyde $(2 \%$ wt.) was added. The thickness of the samples was about $2 \mathrm{~mm}$. The electrospun scaffolds were placed in a plate containing certain amount of the non-cross linked solution of the hydrogel. The solution of the hydrogel was allowed to penetrate into porous structure of the electrospun scaffolds. After 5 minutes, glutaraldehyde was added to crosslink the hydrogel. Based on the constant composition of the hydrogel, here we fabricated three groups of the fiber/hydrogel 
composite; Gel/GP1, Gel/GP2, and Gel/GP3. Fiber/hydrogel composites showed a thickness of about $2 \mathrm{~mm}$.

\section{DNA quantification}

DNA content of the decellularized samples was analyzed using proteinase K (Rajabi-Zeleti et al., 2014). Briefly, the samples were incubated in digestion buffer solution containing 1\% proteinase at $55 \mathrm{C}$ overnight. Then, a phenol/chloroform extraction was performed using centrifuge for 15 minutes at $13700 \mathrm{rpm}$ and the over layer was pick up. In the following step, ethanol 100\% was added and DNA was deposited and separated from the aqueous solution and then washed with ethanol 70\% and then dissolved in RNase-free water. Finally, spectrophotometer (ELISA reader) was applied to determine DNA concentration at $260 \mathrm{~nm}$. We repeated all of the experiments three times for both native and decellularized tissue and reported the average amount of DNA as $\mathrm{mg} / \mathrm{mg}$ dry weight of samples (Rajabi-Zeleti et al., 2014).

\section{Scanning electron microscopy (SEM)}

To study microstructure of the nano fibers and hydrogels, SEM test was employed. Toward this goal, the dried specimens were coated with gold. Then, different parts of the samples were observed to measure fibers diameter and choose the optimum composition based on the absence of granolas.

\section{Contact angle}

To analyze the degree of hydrophobicity of the fibrous scaffold, contact angel test was applied. A drop of water with a specific volume was pipetted and on the surface of fibrous scaffold at room temperature. After $10 \mathrm{~s}$, the angel between the drop and surface was observed using a camera (Dino camera). By analyzing these images with ImageJ, the angle of contact can be measured.

\section{Fourier transform infrared spectroscopy (FTIR)}

Chemical interaction between functional groups of chitosan and ECM in the presence of glutaraldehyde was studied using FTIR test (ABB Bomem-100).

\section{Mechanical properties}

To study mechanical properties of the samples, uniaxial mechanical test was used. Using this method, elastic modulus and maximum shear stress can be obtained. A load (20 N) with a velocity of $0.5 \mathrm{~mL} / \mathrm{min}$ was used for each sample.

\section{Statistical analysis}

In this study, each experiment was performed at least three replicates. We present the obtained data as mean \pm standard error (SE). Statistical analysis was performed by using Oneway analysis of variance (ANOVA) and $P$-values less than 0.05 were considered significant.

\section{Results and discussion}

In recent years, combination of synthetic materials and natural polymers to develop electrospun scaffolds has been widely used (Zhao et al., 2007). PCL is a well-known 
synthetic biomaterial which possess great properties including biocompatibility and mechanical strength. However, its drawbacks such as hydrophobicity and lack of active positions for cell attachment have limited its application in tissue engineering (Cruz et al., 2019). To overcome this challenge, gelatin with high level of cell-recognition domains can be used in combination with PCL (Binulal et al., 2014). In this study, all of the processing parameters related to electrospinning was considered constant as mentioned above.

\section{DNA content}

In the previous studies (Nasiri and Mashayekhan, 2017; Sivandzade and Mashayekhan, 2018; Esmaeili Pourfarhangi et al., 2018), which the same protocol was used to extract ECM from the native tissue, the success of decellularization process was confirmed using Hematoxylin \& Eosin staining test. In this study DNA content of ECM was determined. Figure 1 shows the result of this test for both native tissue (control) and decellularized construct. A significant difference between the samples $(4800 \mathrm{ng} / \mathrm{mL}$ in the heart tissue and $100 \mathrm{ng} / \mathrm{mL}$ in ECM) can be seen which shows that decellularization was performed successfully.

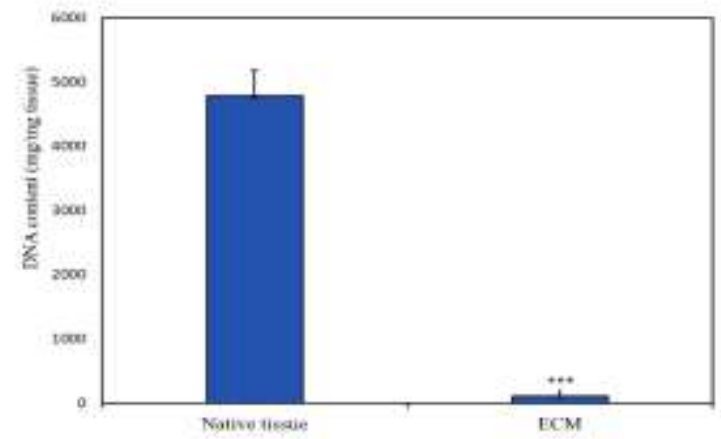

Figure 1. DNA content of the heart tissue and decellularized scaffold $(* * *: P$-value $<0.002)$

\section{FTIR}

Figure 2 shows the results of FTIR test for a combination of PCL and gelatin with mass ratio of 2 (GP2). Based on this figure, peaks at $1639 \mathrm{~cm}^{-1}, 1542 \mathrm{~cm}^{-1}, 1240 \mathrm{~cm}^{-1}$ and, $3300 \mathrm{~cm}^{-1}$ indicates $\mathrm{C}=\mathrm{O}, \mathrm{N} \_\mathrm{H}$ (Amide I), N_H (Amide II), and Amide A bonds, respectively. These peaks are related to gelatin content of the scaffolds. Moreover, two peaks at $2850 \mathrm{~cm}^{-1}$ and $1640 \mathrm{~cm}^{-1}$ are related to $\mathrm{C} \_\mathrm{H}$ and $\mathrm{C}=\mathrm{O}$ bonds, showing PCL. In crosslinking reaction, aldehyde groups (-CHO) of glutaraldehyde reacts with the amino groups of protein lysine. An index of gelatin crosslinking is a graduate color change in the samples from white to yellow. This phenomenon occurs due to the formation $\mathrm{CH}=\mathrm{N}$ bond, which its peak appears in the range $1640-1690 \mathrm{~cm}^{-1}$. It is worth mentioning that cross-linking reaction does not involve any change in the molecular structure of PCL. The similar results have been reported in the previous studies (Pereira et al., 2014; Safaeijavan et al., 2013). We also studied chemical interaction between pure chitosan and ECM using FTIR test (Figure 2b). The main peaks of chitosan can be easily seen at $3439(\mathrm{~N}-\mathrm{H}$ and $\mathrm{O}-\mathrm{H}$ bond), 2925 (CH3 stretch), 1661 (C=O bond), 1438 (C-N), 1155 (C-O-C), and 1073 (C-OH bond) $\mathrm{cm}^{-1}$. FTIR spectra of ECM shows peaks at 1290, 1550, and $1680 \mathrm{~cm}^{-1}$ relating to Amid I, Amid II, and Amid III, respectively. The effect of cross-linking reactions on FTIR spectra of the hybrid 
hydrogel is detectable from the peaks at $1640-1690 \mathrm{~cm}^{-1}$, a slight increase in amid bond at 1103 $\mathrm{cm}^{-1}$, and a significant reduction of peak at $3423 \mathrm{~cm}^{-1}$ corresponding to free amine groups.
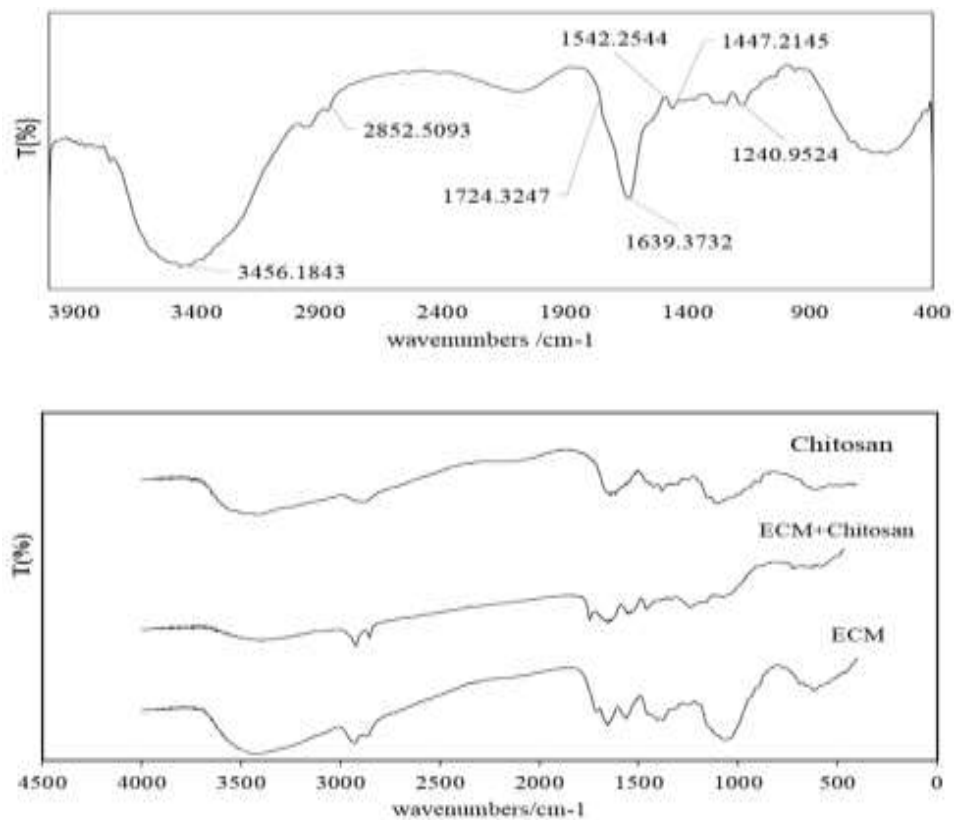

Figure 2. FTIR spectrum of A) PCL/gelatin scaffold and B) pure chitosan, ECM, and hybrid hydrogel

\section{Morphological characterization of the fibrous scaffolds}

The effect of gelatin to PCL ratio on the fiber diameter was studied using SEM. Figure 3 presents the results of SEM test for 3 groups of the fibers. As can be seen, the samples containing the least amount of gelatin showed the lower average diameter $(507.21 \pm 24 \mu \mathrm{m})$ in comparison with other groups (Figure 3a). Moreover, based on Figure 3b-c, the average fiber diameter for 1:2 and 1:3 hybrid mats increased to $580.08 \pm 41$ and $654.99 \pm 49 \mu \mathrm{m}$, respectively.

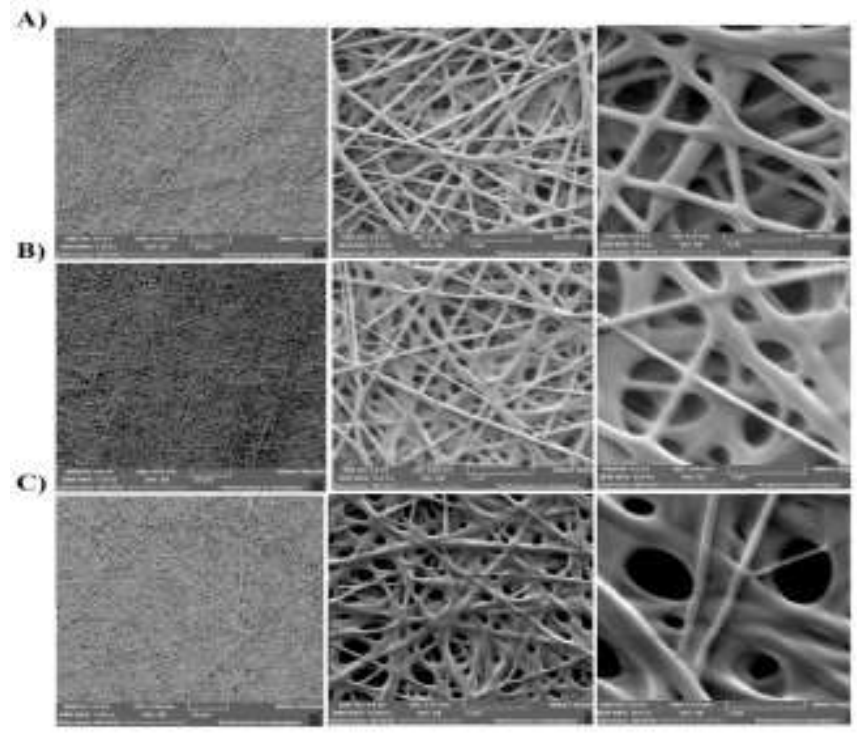

Figure 3. SEM images from the fibrous scaffolds containing different weight ratio of gelatin to PCL of A) GP1, B) GP2, and C) GP3 
Using ImageJ software, the average diameter of three different groups of the electrospun scaffold was estimated. The results of the fiber diameter measurement were shown in Figure 4. From Figure 4, it can be concluded that fiber diameter increased with enhancement of gelatin content in gelatin/ PCL hybrid scaffolds. Given that all processing parameters in spinning were considered constant, the reason of changing in fiber diameter is related to viscoelastic properties of gelatin (Jose et al., 2009). It is well known that viscosity of the polymeric solution is a key parameter that has a significant effect on the fiber diameter because a highly viscoelastic solution requires a high level of tensile force and as a consequence a thick jet and finally a thick fiber is generated (Meechaisue et al., 2006). Furthermore, higher molecular weight of gelatin solution leads a higher viscoelasticity behavior and increases fiber diameter (Aghdam et al., 2014). (Chong et al., 2007) fabricated an electrospun scaffold of PCL and gelatin and observed the same changes in the fibers diameter. They reported that the samples showed an interconnected pores and smooth micro-structure.

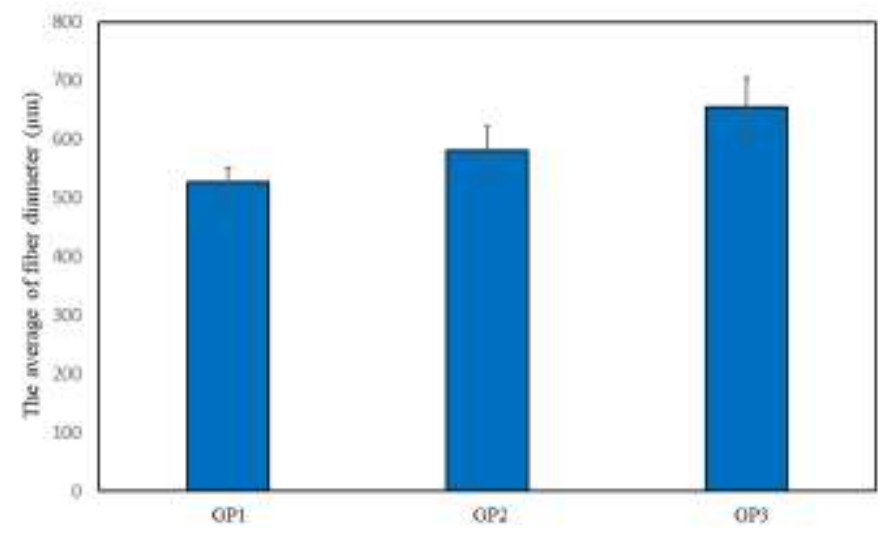

Figure 4. The average diameter of three groups of the produced fibers

\section{Contact angle}

The hydrophilicity and hydrophobicity features of an implantable construct is an influential factor in tissue engineering strategies due to its important effect on different cell behaviors such as attachment and migration (Aghdam et al., 2014). To analyze the influence of gelatin content in the hybrid PCL/gelatin electrospun scaffolds on their hydrophilicity features, contact angle of water drop test was performed. Figure 5 displays the results of contact angle measurements for PCL, PCL/gelatin fibrous samples with various gelatin content.

Based on Figure 5, it can be seen that the contact angel of pure PCL scaffolds is $84^{\circ}$, which indicates that the polymer is hydrophobic and does not absorb water well. By enhancement of gelatin content in the fibrous scaffold, the drop water spread gradually and so, the contact angle was reduced, showing the improved hydrophilicity feature of $\mathrm{PCL} /$ gelatin composites. The reason for this is the abundant presence of hydrophilic groups such as hydroxyl in gelatin molecular structure. Therefore, it is reasonable that the increase of gelatin in the hybrid scaffolds would leads to a significant reduction in the contact angle, showing more hydrophilicity (Aghdam et al., 2014). (Zhang et al., 2005) developed electrospun scaffolds of PCL and gelatin and studied the hydrophilicity 
of two components and its composition. They obtained similar results for gelatin and PCL scaffolds and reported that an improved wettability was observed for gelatin/PCL hybrid scaffolds in comparison with gelatin or PCL alone.

It is shown the combination of PCL and gelatin provides a material with better wettability compared to both pure components. Moreover, because the purpose of this study is to embed these fibers in the hydrogel, the improved hydrophilicity facilitates better interaction between the constituents of the hydrogel.

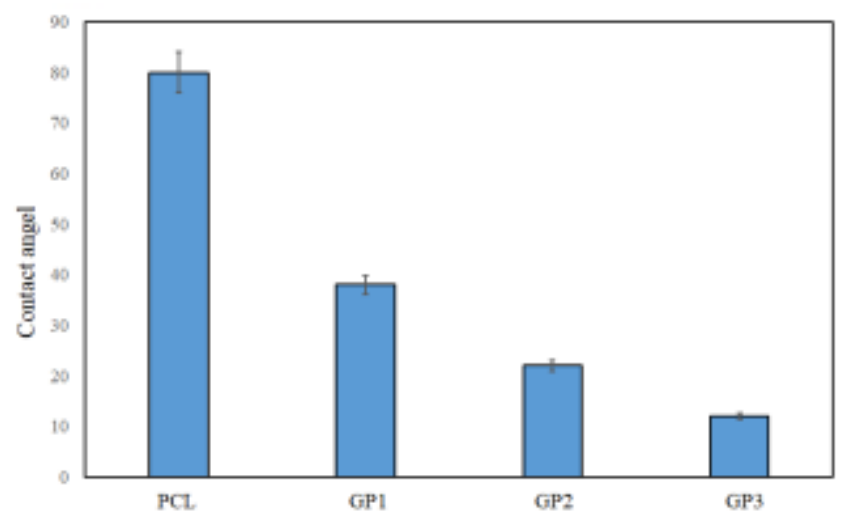

Figure 5. Contact angel of PCL fiber (gelatin to PCL ratio of 0) and GP1, GP2, GP3

\section{Mechanical properties}

Mechanical strength is an important feature of the engineered scaffolds in tissue engineering applications. Because scaffolds should tolerate different forces when are implanted in the body. Moreover, mechanical properties also can direct cell behaviors, which influence tissue regeneration. To control cardiac cell behaviors, it is necessary to develop a scaffold with similar mechanical properties of the heart tissue. Thus, an engineered cardiac tissue should have appropriate Young modulus and sufficient mechanical tensile to resist contracting force of the heart (Vunjak-Novakovic et al., 2010; Dunn et al., 2014).

Figure 6 presents the results of tensile mechanical test of the native heart tissue and different groups of the samples. As shown in this Figure, the nature of PCL scaffold displays a very high stretch, and strong material. As can be seen, gelatin Young's modulus is greater than all of the groups Young's modulus. It can be se en that as gelatin content in the constructs increases the Young's modulus enhances. The similar results have been reported in the previous studies (Zhao et al., 2007; Denis et al., 2015). For example. (Zhang et al., 2005) also reported that the blend of PCL and gelatin produced a higher elongation, energy and Young at break tension point which shows that hybrid scaffolds have appropriate flexibility.

Moreover, it is clear that Young modulus of all samples is much more than that of the native tissue $(31.25 \pm 1.5)$. As mentioned above, an ideal scaffold for cardiac tissue engineering must show a similar mechanical feature. Therefore, it is necessary to embed these electrospun scaffolds in the hydrogels with lower Young modulus. Figure 6 shows the results of tensile test of the fiber/hydrogel composites. 


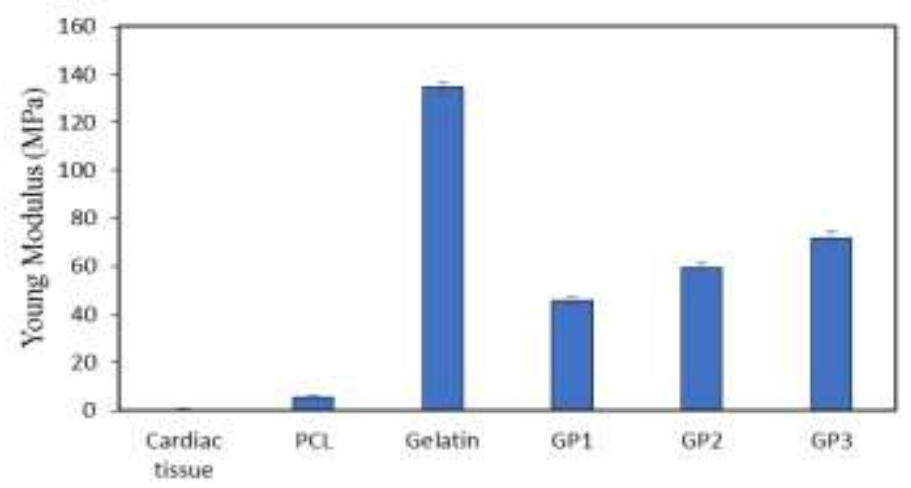

Figure 6. Young's modulus of the native heart tissue, PCL, gelatin, three different groups of the hybrid fibers

According to Figure 7, GP2 embedded in the hydrogel provides Young's modulus of $32.8 \pm 1.3 \mathrm{kPa}$, which is the most similar amount to the native tissue $(31.25 \pm 1.5 \mathrm{kPa})$.

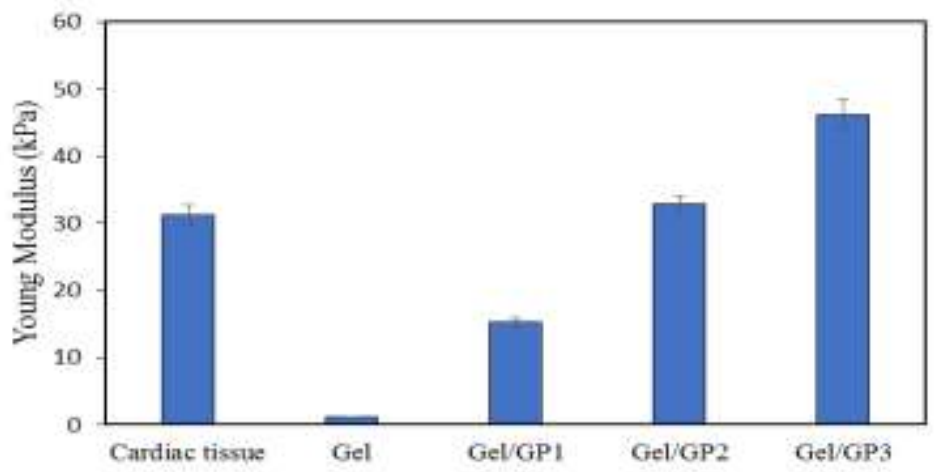

Figure 7. Young's modulus of the native heart tissue, hydrogel of chitosan and ECM (Gel), and fiber/hydrogel composites

\section{Conclusion}

In this study, a promising biomaterial of PCL/gelatin fibers embedded in the hybrid hydrogels of chitosan and ECM was successfully developed for cardiac tissue engineering applications. Microstructure, chemical interactions, contact angel, mechanical properties of the samples were investigated. Young's modulus of GP2 fibrous scaffolds embedded in the hydrogel from chitosan and ECM (mass ratio of 1) was reported to be $31.25 \mathrm{kPa}$, which is very close to the heart tissue. Therefore, this biomaterial can be considered as a potential substrate for cardiac cell culture. However, more in vitro experiments such as MTT assay and in vivo studies are needed to optimize its performance.

\section{References}

Aghdam Mehdinavaz, R, Shakhesi, S, Najarian,S, Malek Mohammadi, M, Ahmadi Tafti, SH, Mirzadeh, H. (2014). Fabrication of a Nanofibrous Scaffold for the In Vitro Culture of Cardiac Progenitor Cells for Myocardial Regeneration. Int. J. Polym. Mater. Polym. Biomater., 63:229239. https://doi.org/10.1080/00914037.2013.800983.

Ahn, S, Ardoña, HAM, Lind, JU, Eweje, F, Kim, SL, Gonzalez, GM, Liu, Q Zimmerman, JF, Pyrgiotakis,

G, Zhang,

$\mathrm{Z}$,

Beltran-Huarac, 
Carpinone, P, Moudgil, BM, Demokritou, P, Parker, KK. (2018). Mussel-Inspired 3D Fiber Scaffolds for Heart-on-a-Chip Toxicity Studies of Engineered Nanomaterials. Anal. Bioanal. Chem., 410:6141-6154. https://doi.org/10.1007/s00216-018-1106-7.

Binulal, NS, Natarajan, A, Menon, D, Bhaskaran, VK, Mony, U, Nair, SV. (2014). PCL-Gelatin Composite Nanofibers Electrospun Using Diluted Acetic Acid-Ethyl Acetate Solvent System for Stem Cell-Based Bone Tissue Engineering. J. Biomater. Sci. Polym. Edit., 25(4):325-340. https://doi.org/10.1080/09205063.2013.859872.

Chong, E, Phan, T, Lim, I, Zhang, Y, Bay, B, Ramakrishna, S, Lim, C. (2007). Evaluation of Electrospun PCL/Gelatin Nanofibrous Scaffold for Wound Healing and Layered Dermal Reconstitution. Acta Biomater, 3(3):321-330. https://doi.org/10.1016/j.actbio.2007.01.002.

Yeyzon, C, Muñoz, E, Gomez-Pachón, EY, Morales-Corona, J, Olayo-Lortia, J, Olayo, R, OlayoValles, R. (2019). Electrospun PCL-Protein Scaffolds Coated by Pyrrole Plasma Polymerization. J. Biomater. Sci. Polym. Edit, 30:832-845. https://doi.org/10.1080/09205063.2019.1603338.

Piotr, D, Dulnik, J, Sajkiewicz, P. (2015). Electrospinning and Structure of Bicomponent Polycaprolactone/Gelatin Nanofibers Obtained Using Alternative Solvent System. Int. J. Polym. Mater. Polym. Biomater., 64(7):354-364. https://doi.org/10.1080/00914037.2014.945208.

Dunn, DA, Alexander JH, Lipke, EA. (2014). Biomimetic Materials Design for Cardiac Tissue Regeneration. Wiley Interdisciplin. Rev. Nanomed. Nanobiotechnol., 6(1):15-39. https://doi.org/10.1002/wnan.1241.

Esmaeili Pourfarhangi, K, Mashayekhan, S, Ghanbari Asl, S, Hajebrahimi, Z. (2018). Construction of Scaffolds Composed of Acellular Cardiac Extracellular Matrix for Myocardial Tissue Engineering. Biologicals, (J. Int. Associat. Biolog. Standardizat.,) 53:10-18. https://doi.org/10.1016/j.biologicals.2018.03.005.

Gautam, S, Dinda, AK, Mishra, NC. (2013). Fabrication and Characterization of PCL/Gelatin Composite Nanofibrous Scaffold for Tissue Engineering Applications by Electrospinning Method." Mater. Sci. Eng. C, 33(3):1228-1235. https://doi.org/10.1016/J.MSEC.2012.12.015.

$\mathrm{Hu}, \mathrm{T}, \mathrm{Wu}, \mathrm{Y}, \mathrm{Zhao}, \mathrm{X}, \mathrm{Wang}, \mathrm{L}, \mathrm{Bi}, \mathrm{L}, \mathrm{Ma}, \mathrm{PX}, \mathrm{Guo}, \mathrm{B}$. (2019). Micropatterned, Electroactive, and Biodegradable Poly(Glycerol Sebacate)-Aniline Trimer Elastomer for Cardiac Tissue Engineering. Chem. Eng. J., 366:208-222. https://doi.org/10.1016/J.CEJ.2019.02.072.

Ismail, HM, Zamani, S, Elrayess, MA, Kafienah, W, Younes, HM. (2018). New ThreeDimensional Poly(Decanediol-Co-Tricarballylate) Elastomeric Fibrous Mesh Fabricated by Photoreactive Electrospinning for Cardiac Tissue Engineering Applications. Polymers. 10(4):455. https://doi.org/10.3390/polym10040455.

Jafarkhani, M, Salehi, Z, Kowsari-Esfahan, R, Shokrgozar, MA, Mohammadi, MR, Rajadas, J, Mozafari, M. (2018). Strategies for Directing Cells into Building Functional Hearts and Parts. Biomater. Sci., 6(7):1664-1690. https://doi.org/10.1039/C7BM01176H.

Jin, J, Jeong, SI, Shin, YM, Lim, KS, Shin, HS, Lee, YM, Koh, HC, Kim, KS. (2009). Transplantation of Mesenchymal Stem Cells within a Poly(Lactide- Co - $\varepsilon$-Caprolactone) 
Scaffold Improves Cardiac Function in a Rat Myocardial Infarction Model. Eur. J. Heart Failure, 11(2):147-153. https://doi.org/10.1093/eurjhf/hfn017.

Jose, MV, Thomas, V, Dean, DR, Nyairo, E. (2009). Fabrication and Characterization of Aligned Nanofibrous PLGA/Collagen Blends as Bone Tissue Scaffolds. Polymer, 50(15):3778-3785. https://doi.org/10.1016/J.POLYMER.2009.05.035.

Kucinska-Lipka, J, Gubanska, I, Janik, H, Sienkiewicz, M. (2015). Fabrication of Polyurethane and Polyurethane Based Composite Fibres by the Electrospinning Technique for Soft Tissue Engineering of Cardiovascular System. Mater. Sci. Eng. C, 46:166-176. https://doi.org/10.1016/j.msec.2014.10.027.

Meechaisue, C, Dubin, R, Supaphol, P, Hoven, VP, Kohn, J. (2006). Electrospun Mat of TyrosineDerived Polycarbonate Fibers for Potential Use as Tissue Scaffolding Material. J. Biomater. Sci. Polym. Edit., 17(9):1039-1056. http://www.ncbi.nlm.nih.gov/pubmed/17094641.

Nasiri, B, Mashayekhan, S. (2017). Fabrication of Porous Scaffolds with Decellularized Cartilage Matrix for Tissue Engineering Application. Biologicals, 48:39-46. https://doi.org/10.1016/j.biologicals.2017.05.008.

Pereira, IHL, Ayres, E, Averous, L, Schlatter, G, Hebraud, A, Ana CCP, Viana, PHL, Goes, AM, Oréfice, RL. (2014). Differentiation of Human Adipose-Derived Stem Cells Seeded on Mineralized Electrospun Co-Axial Poly( $\varepsilon$-Caprolactone) (PCL)/Gelatin Nanofibers. J. Mater. Sci. Mater. Med., 25(4):1137-1148. https://doi.org/10.1007/s10856-013-5133-9.

Pomeroy, JE, Helfer, A, Bursac, N. (2019). Biomaterializing the Promise of Cardiac Tissue Engineering. Biotechnol. Adv., February. https://doi.org/10.1016/J.BIOTECHADV.2019.02.009.

Rajabi-Zeleti, S, Jalili-Firoozinezhad, S, Azarnia, M, Khayyatan, F, Vahdat, S, Nikeghbalian, S, Khademhosseini, A, Baharvand, H, Aghdami, N. (2014). The Behavior of Cardiac Progenitor Cells on Macroporous Pericardium-Derived Scaffolds. Biomaterials, 35(3):970-982. https://doi.org/10.1016/j.biomaterials.2013.10.045.

Safaeijavan, R, Safaeijavan, R, Soleimani, M, Divsalar, A, Eidi, A, Ardeshirylajimi, A. (2013). Biological Behavior Study of Gelatin Coated PCL Nanofiberous Electrospun Scaffolds Using Fibroblasts. J. Paramed. Sci., 5(1). https://doi.org/10.22037/jps.v5i1.5467.

Siddiqui, N, Asawa, S, Birru, B, Baadhe, R, Rao, S. (2018). PCL-Based Composite Scaffold Matrices for Tissue Engineering Applications. Mol. Biotechnol., 60(7):506-532. https://doi.org/10.1007/s12033-018-0084-5.

Singelyn, JM, DeQuach, JA, Seif-Naraghi, SB, Littlefield, RB, Schup-Magoffin, PJ, Christman, KL. (2009). Naturally Derived Myocardial Matrix as an Injectable Scaffold for Cardiac Tissue Engineering. Biomaterials, 30(29):5409-5416. https://doi.org/10.1016/j.biomaterials.2009.06.045.

Sivandzade, F, Mashayekhan, S. (2018). Design and Fabrication of Injectable Microcarriers Composed of Acellular Cartilage Matrix and Chitosan. J. Biomater. Sci. Polym. Edit, 29(6):683-700. https://doi.org/10.1080/09205063.2018.1433422. 
Su, WF, Ho, CC, Shih, TH, Wang, CH, Yeh, CH. (2016). Exceptional Biocompatibility of 3D Fibrous Scaffold for Cardiac Tissue Engineering Fabricated from Biodegradable Polyurethane Blended with Cellulose. Int. J. Polym. Mater. Polym. Biomater., 65(14):703711. https://doi.org/10.1080/00914037.2016.1157802.

Vunjak-Novakovic, G, Tandon, N, Godier, A, Maidhof, R, Marsano, A, Martens, TP, Radisic, M. (2010). Challenges in Cardiac Tissue Engineering. Tissue Eng. B Rev., 16(2):169-187. https://doi.org/10.1089/ten.TEB.2009.0352.

Yang, Y, Wang, C, Wiener, CG, Hao, J, Shatas, S, Weiss, RA, Vogt, BD. (2016). Tough Stretchable Physically-Cross-Linked Electrospun Hydrogel Fiber Mats. ACS Appl. Mater. Interfac., 8(35):22774-22779. https://doi.org/10.1021/acsami.6b08255.

Yang, Y, Wimpenny, I, Ahearne, M. (2011). Portable Nanofiber Meshes Dictate Cell Orientation throughout Three-Dimensional Hydrogels. Nanomed. Nanotechnol. Biol. Med., 7(2):131-136. https://doi.org/10.1016/j.nano.2010.12.011.

Zhang, Y, Ouyang, H, Lim, CT, Ramakrishna, S, Huang, ZM. (2005). Electrospinning of Gelatin Fibers and Gelatin/PCL Composite Fibrous Scaffolds. J. Biomed. Mater. Res., 72B(1):156165. https://doi.org/10.1002/jbm.b.30128.

Zhao, P, Jiang, H, Pan, H, Zhu, K, Chen, W. (2007). Biodegradable Fibrous Scaffolds Composed of Gelatin Coated Poly( $\varepsilon$-Caprolactone) Prepared by Coaxial Electrospinning. J. Biomed. Mater. Res. A, 83A(2):372-382. https://doi.org/10.1002/jbm.a.31242.

How to cite this article: Shohreh Mashayekhan, Mahboubeh Jafarkhani, Saeed Moghadam, Reinforcement of a Decellularized Extracellular Matrix-Derived Hydrogel Using Nanofibers for Cardiac Tissue Engineering. International Journal of Advanced Biological and Biomedical Research, 2020, 8(3), 302-313. Link: http://www.ijabbr.com/article 38286.html 